\title{
Dimensiones Básicas de un Desarrollo Humano Integral
}

\author{
Miguel Martínez Miguélez*
}

Resumen. El ser humano es un suprasistema altamente complejo, pero más o menos integrado. El nivel de integración armónica determina el grado de desarrollo y madurez de su personalidad. Todo esto impone a la educación una tarea o misión sumamente ardua y difícil, en la cual frecuentemente fracasan muchos educadores y otros profesionales que trabajan en el desarrollo humano. La superación de dichas dificultades estriba en un conocimiento teórico-práctico de los diferentes niveles de las áreas a desarrollar en las profesiones de ayuda. Ésta es la labor que trata de ilustrar este breve estudio asumiendo un enfoque psicológico y pedagógico.

Palabras clave: desarrollo humano, madurez, educación, orientación.

\section{Basic Dimensions of an Integral Human Development}

\begin{abstract}
Human beings are a highly complex suprasystem, but more or less integrated. The level of harmonic integration determines their personality development and maturity degree. All these imposses an extremely arduous and difficult task or mission to education, in which frequently many educators and other professionals, that work in human development, fail. The overcoming of theses difficulties rests on a theoretical and practical knowledge about the different levels of the areas to be developed in professions focused on helping. This is the task that this brief study tries to illustrate, assuming a psychological and pedagogical approach.
\end{abstract}

Key words: human development, maturity, education, counseling.

Recibido: 22.05.2009

Aceptado: 17.06.2009

$* * *$

\section{Visión de Conjunto}

El auténtico “desarrollo humano” siempre ha sido sesgado a través de la historia, en una u otra dirección, con una u otra perspectiva limitante que, a veces, dejan fuera de su vista aspectos centrales y fundamentales del mismo. Por ello, la “educación” así “desarrollada” quizá merezca otro nombre menos ilustre y, sobre todo, menos comprometedor.

El ser humano, como todo ser vivo, no es un agregado de elementos yuxtapuestos; es un todo integrado que constituye un suprasistema dinámi-

\footnotetext{
*Universidad Simón Bolívar, Caracas, Venezuela). E-mail: miguelm@usb.ve.
} 
co, formado por muchos subsistemas perfectamente coordinados: el subsistema físico, el químico, el biológico, el psicológico, el social, el cultural, el ético-moral y el espiritual. Todos juntos e integrados constituyen la personalidad, y su falta de integración o coordinación desencadena procesos patológicos de diferente índole: orgánica, psicológica, social, o varias juntas.

Por esto, el llevar a un ser humano a su pleno desarrollo y madurez, en su realidad integral, constituye la empresa más difícil y ambiciosa que pueda proponerse una persona, una institución e, incluso, una sociedad completa. Sin embargo, caminar en esa dirección, abriendo horizontes e iluminando caminos, es la meta que se propone, en general, toda verdadera educación y desarrollo pleno del ser humano.

El cerebro de un simple animal está formado por áreas perfectamente delimitadas y circunscritas: son áreas comprometidas con un desempeño genéticamente determinado para mantener su vida en perfecto estado y propagar la especie. El cerebro del ser humano, en cambio, está compuesto prevalentemente por áreas no comprometidas, disponibles para el desempeño y funciones que adquiere a través de la formación familiar y social; y es un hecho desafiante el que sólo una mínima parte de estas áreas no comprometidas (inferior, quizá, a un 10\%) se desarrolle plenamente. Esta diferencia y situación señalan los alcances y posibilidades sin límites que se le ofrecen al ser humano por su misma estructura genética cerebral. Indica, asimismo, la magnitud de las metas y el nivel de los objetivos de su posible desarrollo futuro. Por ello, todo desarrollo del ser humano deberá tener en cuenta, en su programación, primero, las posibilidades del mismo y, en un segundo lugar, los medios más adecuados que faciliten y conviertan en realidad ese posible desarrollo.

En este sentido, el concepto mismo de desarrollo, cuando está referido al ser humano, debe ser bien entendido. Deberá ser entendido en sentido estricto (como despliegue o desenvolvimiento) en los niveles de las estructuras físicas, químicas y biológicas; pero deberá ser entendido en sentido sólo metafórico al referirse a la configuración de estructuras psíquicas, sociales, culturales, éticas, espirituales u otras de nivel superior, ya que, en este nivel, no existe una sola meta prefijada genéticamente, como es el caso de las estructuras inferiores, sino múltiples posibilidades, entre las cuales se deberá escoger basándose en criterios u opciones y alternativas, unas veces de naturaleza ideológica y otras, incluso, con trasfondo ético.

La amplitud y complejidad del desarrollo humano ha propiciado que múltiples disciplinas se hayan abocado a estudiar y tratar de desentrañar su realidad y enigmática naturaleza. La filosofía de la educación, la pedagogía, la biología genética, la psicología del desarrollo, la sociología educativa y muchas otras han dado aportes muy valiosos para guiar la acción práctica de las profesiones de ayuda. ¿Qué líneas 
matrices se derivan de estos esfuerzos e investigaciones interdisciplinarias?

La filosofía griega creó una imagen del hombre centrada en la virtud y la razón: el hombre alcanzaba la virtud a través del uso de la razón y siguiendo sus demandas. El pensamiento cristiano le añadió los conceptos de amor y pecado. El Renacimiento introdujo los aspectos de poder y voluntad, plasmando la imagen política del hombre. Los siglos XVIII y XIX racionalizaron el interés de los hombres por la propiedad, las cosas $\mathbf{y}$ el dinero. La imagen freudiana de la primera mitad del siglo XX enfatizó el aspecto impulsivo, irracional e inconsciente del ser humano, y la psicología conductista puso el acento en la presión que ejercen los factores ambientales. Pero nunca como en los tiempos actuales se enfatizó tanto la necesidad de la armonía y convivencia cívicas, como lo hace la Psicología Humanista (Martínez, 2004). Por ello, esa armonía de áreas del desarrollo humano es la que trata de ilustrar este breve estudio, ponderando la importancia y función de cada una de ellas.

El filósofo Baruch Spinoza afirmó que "el hombre es un animal social", pero los pensadores existencialistas han puesto un énfasis particular en los dilemas que vive el hombre contemporáneo en una sociedad de masas y estandarizada, en la cual se siente como enjaulado, alienado y deshumanizado. En esa situación, aunque rodeado de gente por todas partes, el individuo se siente solo ante su propia existencia, que le obliga a encarar sus dudas, miedos y ansiedades, y busca la compañía de los demás como un medio para superar su soledad. Así, esta tendencia, natural en el hombre, se ve aumentada en los últimos tiempos.

Este cambio básico en nuestra sociedad, que hace de todo ser un ser-en-relación, donde cada entidad social está constituida por un grupo de relaciones que tiene con las demás entidades, requiere paralelamente un cambio en la educación. La nueva educación debe fijar como una prioridad el sentido y conciencia de la propia responsabilidad, es decir, ser sensible y percatarse de la repercusión positiva o negativa que la conducta individual tendrá en las demás personas.

Durante los últimos 20 años, la UNESCO, como Organización de las Naciones Unidas para la Educación, la Ciencia y la Cultura, viene insistiendo en una serie de ideas de máxima relevancia (Ciret-UNESCO 1997, 2000, UNESCO 1979, 1998a, 1998b). Entre esas ideas están las siguientes afirmaciones:

• Los Países en Desarrollo sólo lo alcanzarán con una calificada y competente preparación de sus profesionales.

* La desorientación de la Universidad es un fenómeno mundial.

- Los cambios mundiales tienen un ritmo acelerado.

* La lógica clásica y pensamiento único generan pobreza.

. No podemos seguir parcelando el saber; necesitamos un enfoque transdisciplinario. 
• Es urgente una visión trans-nacional, trans-cultural, trans-política y trans-religiosa.

. Debemos adoptar un paradigma sistémico para la complejidad.

* Es necesario rehacer los Planes de Estudio.

* El Diálogo como Método es imprescindible

Arriba señalamos que el "desarrollo humano" siempre ha sido sesgado a través de la historia. En efecto, McLuhan dice: "no sé quién descubrió el agua por primera vez, pero estoy seguro que no fueron los peces". Todos llevamos una cultura y una historia a cuestas, como un agua que nos rodea y en la que vivimos, con todas sus implicaciones para nuestro proceso cognitivo, impregnada de valores, creencias, intereses, sentimientos, etc. Por ello, aun cuando se trate de Organismos de gran prestigio, como lo es, en nuestro caso, el PNUD, al fijar unos "indicadores para definir el desarrollo humano” con pocos conceptos -una vida más larga, más saludable y más plena-, inmediatamente pedimos que se explicite el contenido conceptual de cada uno de estos componentes; y es aquí donde se ubica el problema. Efectivamente, nuestra mente inquisitiva quiere ver cuántos y cuáles son los factores que entran en juego y, sobre todo, qué función desempeña cada de ellos en esa compleja y enmarañada red estructural y semántica de relaciones que se forma, pues no se trata únicamente de algo multidimensional (asumiendo este término en su acepción estricta: geométrica), sino, y sobre todo, de algo mucho más complejo, como son las interacciones continuas entre sus variados factores.

Ahora bien, esta línea de reflexión desemboca por su propia naturaleza en la exigencia de un cambio de paradigma epistémico, en la necesidad de adoptar un paradigma sistémico (como nos pide la UNESCO desde 1979) para enfrentar la alta complejidad con que se nos presentan las realidades del mundo actual y, especialmente en el proceso educativo, pues, como dice Ludwig von Bertalanffy, "desde el átomo hasta la galaxia vivimos en un mundo de sistemas” (1981:47).

Ya desde la segunda parte del siglo XX, la filosofía de la ciencia se centró en este estudio epistemológico, y, en la sola década de los 60 , le dedicó cinco simposios internacionales que concluyeron levantando lo que se ha llamado el acta de defunción de la concepción heredada (el positivismo lógico), la cual, a partir de ese momento, según Popper, “quedó abandonada por casi todos los epistemólogos", debido "a sus dificultades intrínsecas insuperables” (1977:118). Esta posición se puede resumir en el título que Edgar Morin pone en una reciente obra suya: La cabeza bien puesta (2002), y que Einstein llamaba "saber pensar". Por nuestra parte, ese arduo problema básico lo enfrentamos a fondo en una obra que ha tenido ya tres ediciones y más de una docena de reimpresiones, traducida también al inglés (1993¹ $1997^{2}$, 2006c).

Dentro de la brevedad de estas páginas, tendremos presentes estas ideas como trasfondo y contexto para la poliédrica figura de un "desarrollo humano integral”, conscientes de que sólo captamos algunas caras de 
ella y que necesitamos un diálogo fecundo con otros enfoques que las complementan.

\section{Desarrollo Neurofisiológico}

Un adecuado desarrollo biológico del organismo humano requiere, desde los albores de su conformación inicial, un cuidado, un esmero y una atención muy especiales, tanto mayores cuanto más nos acercamos al origen. Una dieta deficitaria o mal balanceada en la madre gestante, o en los primeros años de la vida del niño -cuando se estructuran las neuronas y muchas de sus conexiones sinápticas-, es crítica, y ha sido identificada como la responsable de daños cerebrales irreparables y malformaciones irreversibles, o la base de enfermedades congénitas de diferente índole, ya que queda limitado el sistema inmunológico general. El organismo humano, y sobre todo el cerebro humano, para su correcta formación y estructuración, requiere proteínas, carbohidratos, grasas, minerales y vitaminas en un equilibrio ordenado. No puede, por consiguiente, esperarse una población sana y vigorosa allí donde reina una pobreza alimentaria extrema. Más bien, veremos que abundarán enfermedades como la diabetes, la arteriosclerosis prematura, la cirrosis y otras, y, en el área psicológica, la apatía mental, la incapacidad de atención, la somnolencia y, en general, una reducción de las facultades mentales, para las cuales, aunque se puedan encontrar muchos orígenes, el más frecuente de ellos es precisamente la deficiencia y desorden nutricionales.

Si los responsables del desarrollo y educación infantiles pudieran atender eficazmente este solo problema, movilizando, para conseguirlo, los entes gubernamentales y privados que la situación requiera, pudieran sentirse ampliamente satisfechos y orgullosos, porque con ello pondrían las bases para el fácil logro de innumerables objetivos en muchas otras áreas y campos de la vida humana.

Si a una dieta rica y bien balanceada podemos añadir, aunque sea en menor proporción, cierto nivel de salubridad y comodidad habitacional, estaremos en el camino correcto para asegurar un adecuado y sano desarrollo físico, químico y biológico.

Son muchos los autores e investigadores que han demostrado que la falta de desarrollo estructural lleva luego a una incapacidad funcional. Sperry lo especifica en los siguientes términos: "muchos elementos internos de nuestro cerebro se activan solamente con operaciones muy específicas y, si estas actividades no se realizan (de una manera particular durante las etapas del desarrollo infantil y juvenil cuando las neuronas y sus sinapsis dependen mucho del uso), las neuronas involucradas pueden sufrir un proceso regresivo, dejando profundas deficiencias funcionales en su maquinaria integradora” (Bogen, 1976). Esto explicaría tantos hechos y constataciones de "desventajas culturales", es decir, de personas cuyas potencialidades han quedado sin desarrollar por falta de una "escolaridad apropiada". 
Aunque desconocemos cuál es lo máximo que puede lograr la mente humana, ya que parece algo sin límites, por lo que calculan las investigaciones más recientes, es de tal magnitud que el hombre normal y corriente sólo desarrolla entre el 5\% y el 7\% de sus posibilidades. Sin embargo, este porcentaje se puede hasta quintuplicar en condiciones óptimas de orquestación didáctica, es decir, tratando de optimizar la intervención de los tres cerebros (hemisferio izquierdo, derecho y sistema límbico) en un equilibrio armónico y de acuerdo a la materia, disciplina, asignatura o programa a enseñar. Pero todo docente puede constatar cuán difícil le resulta eso en los casos en que las fallas tienen antecedentes biológicos de los primeros años de vida: mala nutrición y ausencia de una escolaridad o ejercicio apropiados.

\section{Desarrollo Cognitivo, Inteligencia y Creatividad}

Los procesos cognitivos, en general, como el pensamiento original creativo y productivo, no son acciones aisladas en las personas, sino que impregnan toda la personalidad; es decir, no son algo que se toma o se deja, que se entrena o se adquiere en un momento, como en un "taller para enseñar a pensar", en un "taller de creatividad", en una "semana de la creatividad” y cosas por el estilo. El verdadero proceso cognitivo, la verdadera creatividad, son procesos favorecidos y propiciados por un clima permanente de libertad mental, una atmósfera general, integral y global que estimula, promueve y valora el pensamiento original, divergente y autónomo, la discrepancia razonada, la oposición lógica, la crítica fundada. Como podremos constatar, todo esto es algo que se proclama mucho de palabra, pero que se sanciona severamente de hecho en todos los niveles de nuestras estructuras "educativas". Siempre es peligroso defender una opinión divergente. Los representantes del estatus (en cualquier área) toman sus precauciones contra esos “fastidiosos perturbadores del orden”. Debido a ello, no resulta nada fácil forjarse una opinión propia. Esto exige esfuerzo y valentía.

Frecuentemente se ha definido al hombre como un "animal racional”; esta definición nos ha sido transmitida por la cultura helénica y tiene como fuente la filosofía de Aristóteles. Se considera su inteligencia, su razón y su lógica como la nota distintiva. Si el hombre tiene un comportamiento diferente, es decir, no guiado por esa "parte lógica y racional", se dice que el hombre procede en forma irracional, e, incluso, en forma antirracional. Pero el ser humano puede también seguir un tercer procedimiento que no es racional ni irracional, sino simplemente arracional, es decir, prescinde o no sigue "la razón”, la cual -bien analizada- puede ser un simple hábito mental, una costumbre o una mera rutina mental. Hoy día hay fuertes teorías que consideran el sistema cognitivo y el afectivo como un solo sistema, la estructura cognitiva-emotiva. Ya Pascal había afirmado que "la pasión obnubila la razón" (Pensamiento 73). De esta manera, los estados afectivos adquieren una importancia extraordinaria, ya que pueden inhibir, distorsionar, excitar o regular los procesos cognoscitivos, 
conclusión ésta que deberá cambiar muchas prácticas antieducativas, que no se preocupan de crear el clima o atmósfera afectivos necesarios para facilitar los procesos de aprendizaje y el fomento y desarrollo de la creatividad.

Es plenamente natural al ser humano el comportarse en forma creadora. Aún más, ésta es la nota más distintiva y específica que lo contradistingue del animal. La actividad creadora no es algo reservado a personas ricamente dotadas o excepcionales: todo ser humano normal puede desempeñarse creativamente en mayor o menor grado. Torrance (1971) puntualiza que el pensamiento creativo consiste en el proceso de percibir elementos que no encajan o que faltan, de formular ideas o hipótesis sobre esto, de probar estas hipótesis y de comunicar los resultados, tal vez modificando y volviendo a probar la hipótesis. El Premio Nobel de medicina Szent-Györgyi dice que "el pensamiento creador consiste en ver lo que todo el mundo ve y pensar lo que nadie piensa”. De esta manera, la realización creativa tendría un carácter novedoso y original, podría ser más o menos extraordinaria y, de alguna manera, enriquecería con su aporte a la sociedad y a la cultura.

Quizá, la falla mayor de nuestra educación, en la cultura occidental, haya consistido en cultivar, básicamente, un solo hemisferio, el izquierdo, y sus funciones racionales conscientes, descuidando la intuición y las funciones holistas y gestálticas del derecho, e, igualmente, marginando la componente emotiva y afectiva y su importancia en el contexto general. Así, mientras en un nivel llevamos una existencia que parece racional y cuerda, en otro nivel estamos viviendo una existencia rabiosa, competitiva, miedosa y destructiva. La armonía entre las tres partes del cerebro, entre sus tres estructuras fundamentales, su equilibrio y sabia orquestación, deberá ser un objetivo fundamental de nuestra educación moderna.

Por este camino, nos enfrentamos a dos conceptos: la inteligencia y la sabiduría; y es importante puntualizar algunos de sus aspectos para mayor clarificación: la sabiduría, se distingue de la inteligencia. La inteligencia se centra mucho en el uso del conocimiento; la sabiduría, en cambio, es muy consciente de los supuestos que acepta y de sus propios límites. La persona inteligente cae fácilmente en la automatización y la valora; la persona sabia se resiste a la automatización del pensamiento y trata, más bien, de contrarrestarla. Es posible, por otra parte, ser dogmático e inteligente al mismo tiempo, pero no dogmático y sabio; los asesores dogmáticos tienden a ser ineficaces. Es más, muchos aspectos de la inteligencia, cuando no van guiados por la prudencia, pueden incluso tener un efecto nocivo en el proceso de ayuda. Asimismo, la inteligencia, en general, se desentiende de los sentimientos y su función, mientras que la sabiduría tiende a integrar el pensamiento y los sentimientos en un todo óptimo, como señalan los recientes estudios de Goleman (1996) sobre lo que él llama “inteligencia emocional”.

En el campo de la profesión docente, por ejemplo, es muy grande el daño que podemos hacer a nuestros estudiantes basándonos en una "racio- 
nalidad” endiosada (la diosa razón del siglo de las Luces), que, más que una auténtica razón, está constituida por hábitos y rutinas mentales, repetidos sin mucha conciencia de su origen, como hacen los "repetidores de oficio”.

Popper clarifica esta posición, al decir:

En los años veinte comprendí lo que la revolución einsteniana significó para la epistemología: si la teoría de Newton, que estaba rigurosamente probada, y que se había corroborado mejor de lo que un científico nunca pudo soñar, se reveló como una hipótesis insegura y superable, entonces no había ninguna esperanza de que cualquier teoría física pudiese alcanzar más que un estatus hipotético, o sea una aproximación a la verdad (en: Rivadulla, 1986, p. 297).

\section{Desarrollo Psicológico, Afectivo y Social}

Pero, al lado de todo esto, necesitamos, paralelamente, un apropiado desarrollo psicológico, afectivo, social y cultural. Precisamente, este “desarrollo” es el que se va a instalar en las áreas no comprometidas del cerebro humano. Pero, ¿cómo lograr esta empresa y hacerlo en forma eficiente y admirable?

De un examen y análisis de las ciencias humanas antes mencionadas y de otras que se han preocupado de alguna faceta relacionada con el desarrollo humano, podemos señalar dos núcleos centrales de proposiciones: el primero ilustra, sustancial y básicamente, que, en igualdad de condiciones, estos aspectos del desarrollo humano son directamente proporcionales a la variedad de oportunidades de interacción que le proporcione el medio ambiente. Es decir, que la dotación genética heredada por el ser humano va a tener un mayor número de interacciones con el medio de acuerdo a la variedad y riqueza de éste (dotación de medios en el hogar, en el preescolar, en su ambiente socio-cultural, etc.) y, consecuentemente, el nivel de logros alcanzados en estos sectores (desarrollo lingüístico, intelectual, emocional, estético, ético, etc.) dependerá de la magnitud de ese factor.

El otro núcleo central de proposiciones está ligado con la atmósfera o clima afectivo que se cree en ese medio ambiente y que se le ofrezca al ser humano en desarrollo. Pareciera que la riqueza del medio se acentúa, aumenta su efecto, funciona mejor o interactúa más intensamente con la dotación genética, cuando hay un clima afectivo cálido, lleno de cariño, de afecto y de ternura, acogedor y que inspira confianza. Este clima cálido, esta atmósfera acogedora crean una armonía y equilibrio hormonal y endocrino que dan como resultado un desarrollo óptimo y sano. Ya el gran pedagogo suizo Johann Pestalozzi, hace dos siglos, se había adelantado a esta constatación cuando afirmó: “el amor es la única y eterna base sobre la cual se puede formar humanamente nuestra naturaleza”. Hoy día, podemos añadir, con fuertes argumentos de respaldo, que ese amor no sólo es la clave de 
un desarrollo humano armónico para el niño, sino que también es la base de una vida feliz en los adultos y el ingrediente indispensable de las mejores terapias psicológicas cuando los trastornos psíquicos han invadido su existencia.

Contrariamente a lo que sostuvieron algunas teorías pesimistas sobre la naturaleza humana, hoy podemos demostrar que el niño nace bueno y se orienta espontáneamente hacia el bien, como un ser humano cordial, cooperante y armónico, cuando se le brinda lo que le pide naturalmente su propio organismo: alimento y cariño; es decir, lo que su ser necesita física, química y biológicamente, por un lado, y psíquica, social y espiritualmente, por el otro. Toda la psicología humanista de Carl Rogers avala y respalda esta posición (1972, 1975, 1980a, 1980b).

Este clima o atmósfera emotiva óptima se da cuando el docente logra en su clase un ambiente de alegría y felicidad, con ausencia de tensión, de estrés, de amenaza y de ansiedad. El mismo Einstein decía que "el arte más importante de un maestro es saber despertar en sus alumnos la alegría de conocer y crear". Si este ambiente no se da, el sistema endocrinovegetativo y el sistema límbico inhiben gran parte de la actividad mental del córtex prefrontal y dedican su energía ideando y haciendo todo tipo de combinaciones asociativas con el fin de protegerse de la inseguridad, miedo y hasta pánico que experimentan algunos niños y estudiantes ante sus docentes. La serenidad y paz emocional, en cambio, crea las condiciones para una tranquila actividad mental, intelectual, mnemónica y creativa, libre de la tensión que agota y consume un alto nivel de energía.

\section{Desarrollo Moral, Ético y de Valores}

El movimiento humanista en las diferentes ciencias humanas ha ido logrando a nivel mundial una serie de "frutos" de amplísima repercusión, tanto a nivel de derechos humanos, del niño, de la mujer, como a nivel de acuerdos políticos, de desarme, de comercio, de reducción del colonialismo, etc.

Como una especie de definición orientadora, pudiéramos decir que la Educación Humanista es aquella en la cual todas las facetas del proceso de desarrollo humano ponen un énfasis especial en las siguientes realidades: unicidad de cada ser humano, tendencia natural hacia su auto-realización, libertad y auto-determinación, integración de los aspectos cognitivos con el área afectiva, conciencia y apertura solidaria con los demás seres humanos, capacidad de originalidad y creatividad, y jerarquía de valores y dignidad personales. Éstas deberán constituir las metas hacia cuyo logro se orientarán las acciones de los "educadores" en el "aula planetaria" en que vivimos. En esta aula abierta y universal son "educadores", para bien o para mal, todas las personas que ocupan cargos o posiciones públicas o que tienen una vida o comportamiento que está a la luz de sus conciudadanos. Como dice un sabio adagio pedagógico, "las palabras mueven, pero los ejemplos arrastran”. 
Al analizar unas doscientas biografías, la gran psicóloga humanista Charlotte Bühler (1967) observó que cada vida estaba ordenada y orientada hacia uno o varios objetivos. Cada individuo tenía algo especial por lo que vivía y trabajaba, un propósito principal, una misión, una vocación, una meta trascendente, que podía variar mucho de un individuo a otro. En cada persona existía un proceso evaluador interno que iba estructurando un sistema de valores, el cual, a su vez, se convertía en el núcleo integrador de la personalidad y formaba una filosofía unificadora de la vida. Para Allport, "el valor es una creencia con la que el hombre trabaja de preferencia. Es una disposición cognitiva, motora y, sobre todo, profunda de su propio yo" (1966:530).

En medio del cúmulo de incertidumbres, dudas y probabilidades que rodean al ser humano, es lógico que éste busque algunos puntos de anclaje, algunas certezas, alguna fe, que le sirvan como guía que ilumina su camino o como bálsamo benéfico que mitigue las inevitables frustraciones y ansiedades que la vida engendra.

Solschenitzin dijo, no hace mucho tiempo, que "el mayor defecto de la democracia occidental es su falta de una base ética; que los partidos y las clases sociales se lanzan a pelear en un conflicto de intereses y nada más que intereses; que la democracia occidental está viviendo una gran decadencia” (1974).

Ya durante el siglo XIX, pero, sobre todo, en el XX, la división del trabajo ha seguido un ritmo siempre "in crescendo", debido a la explosión de los conocimientos y a la urgencia de una mayor especialización. Los catálogos de profesiones de los países más avanzados llegan a numerar entre 10 y 30 mil profesiones. Esto ha traído consigo la posibilidad de que la mayoría de los profesionales, científicos y técnicos que egresan de nuestras universidades queden deformados por una especialización cada vez más estrecha y vivan en un mundo espiritual ínfimo. El mundo cultural, moral y ético en que asientan sus vidas es prácticamente inexistente.

Como la vida es siempre actualísima, urgente y no puede esperar, si el hombre no posee a la mano la solución que las grandes disciplinas culturales ofrecen a sus problemas, elaborará una cultura y una ética basada en slogans, estereotipos y lugares comunes. Esto lo hace frecuentemente el hombre de la calle, pero lo puede hacer con igual frecuencia el profesional inculto.

Ortega y Gasset considera al universitario inculto que así procede como "el nuevo bárbaro, retrasado con respecto a su época, arcaico y primitivo en comparación con la terrible actualidad y fecha de sus problemas. Este nuevo bárbaro es principalmente el profesional, más ‘sabio’ que nunca, pero más inculto también: el ingeniero, el médico, el abogado, el científico”. Para él la “cultura es lo que salva del naufragio vital, lo que permite al hombre vivir sin que su vida sea tragedia sin sentido o radical envilecimiento" (1968). Y añade que "ha sido menester esperar hasta los comienzos del siglo XX para que se presentase un espectáculo increíble: el de la 
peculiarísima brutalidad y la agresiva estupidez con que se comporta un hombre cuando sabe mucho de una cosa e ignora de raíz todas las demás” (ibíd., p. 34).

Esta muestra axiológica, saturada de verdaderos antivalores, refleja la estructura de la sociedad consumista creada por una técnica desprovista de orientación y altos fines, como serían, en nuestros países, la erradicación de la miseria, el hambre, la enfermedad y la ignorancia.

Ante esta situación de facto, ¿ pueden la Educación y la Universidad contemporánea desentenderse de su misión de ofrecer a sus estudiantes un sistema de ideas vivas que represente el nivel cultural de su tiempo? Todo dependerá del valor que sus autoridades reconozcan a esta formación humanista, cívica y espiritual, en relación y comparación con la preparación profesional y el entrenamiento en la investigación.

\section{Desarrollo Vocacional y Profesional}

Autogestión. A estas ideas centrales sobre la optimización del desarrollo humano, conviene añadir una más, pensando, especialmente, en el modo de gerenciarlas: la autogestión asistida. Pareciera que todo lo dicho implicara una gestión desde arriba y desde afuera y, sin embargo, la verdadera eficacia proviene de la idea contraria. Los gerentes de la educación no deben crear una jerarquía de mando, y, menos aún, hacer de puente y traer del extranjero las políticas de desarrollo o, peor todavía, dejar que se las impongan desde el exterior. Como decía Ortega, "debemos buscar en el extranjero información, pero no modelos”.

La buena gerencia educacional deberá lograr una auténtica participación de las comunidades asistidas, en el diseño, en la gestión y en la evaluación de los programas que se proponen. Cuando la comunidad participa en todo el proceso de un proyecto, hace suyo el éxito o el fracaso y, por ello, entrega lo mejor de sí misma para el logro de los fines deseados. El rol del profesional de la educación -ya sea que se trate de enriquecer o mejorar el área nutricional, educacional, habitacional, de la salud o, en general, del desarrollo humano individual o grupal- debe ser el que dicta la mayéutica socrática, pues está suficientemente demostrado que toda comunidad, por muy humilde que sea, cuando se le ofrecen las condiciones adecuadas y oportunas, genera verdaderas y auténticas soluciones a sus problemas cotidianos. Ese proceso irá convirtiendo, además, a sus miembros, poco a poco, en seres autosuficientes y forjadores de su propio destino, que es la meta más ambiciosa de todo posible desarrollo humano.

Una de las prácticas que están más fuera de sentido -salvo en situaciones y áreas muy específicas-son los "entrenamientos mentales”. El know how puede convertirse en una capitis diminutio: es decir, que cuanto más aprendemos a hacer una cosa de una determinada manera, más incapaces nos volvemos para hacerla de otra forma. No hay modo de descubrir las 
necesidades futuras, sino a muy corto plazo, ya que la complejidad de la vida actual crea muchas situaciones incontrolables e impredecibles, llenas de incertidumbre y de azar. Esto cuestiona los currículos y programas fijos; por ello, los entrenamientos a largo plazo son inadecuados, ya que cautivan el futuro; más bien, se hace necesaria una actualización continua. En sentido estricto, los entrenamientos son propios de los animales por ser incapaces de ver las razones de las cosas: el almirante Rickover, quien diseñó y dirigió el primer submarino atómico, el Nautilus, decía que un mono adiestrado podía manejarlo. En consecuencia, conviene señalar que muchas instituciones escolares están preparando a sus estudiantes para un mundo que ya no existe, un mundo que ya se fue. Y muchos de los encuentros de grupos que se dan frecuentemente en el campo social están orientados hacia el entrenamiento, logro de metas y adquisición de técnicas que sean efectivas para alcanzar determinados intereses y control social, y, así, no tienen como mira el crecimiento personal y, menos aún, la emancipación de los participantes, ya sea como individuos o como comunidad.

Hoy día, además, ya no hay necesidad de poner en el cerebro, ocupando lugar, nada que pueda estar en una estantería, disco duro, pendrive o en la red de Internet. Tenemos una biblioteca universal a nuestra disposición y está compuesta por todas las fuentes de información disponibles: bibliotecas, Internet, TV, radio, cine, libros, congresos y publicidad, entre otros. Y el mundo entero se ha convertido en lo que McLuhan llama el "aula sin muros", es decir, la oficina, la fábrica, la empresa, la agencia, la hacienda, etcétera. La información está ahí, el ambiente está lleno de ella; lo que hay que hacer es aprender a jugar con sus elementos, desarrollando la creatividad y la originalidad. El mismo Einstein decía que su Teoría de la Relatividad se habría podido formular 50 años antes, pues todos sus elementos eran de dominio público; que lo que él había hecho era "jugar con sus componentes"; claro, ¡tremendo jugador! Sin embargo, lo que hacen muchos profesores es generar ambientes ricos en estímulos informativos, pero pobres en experiencias creadoras; estos ambientes sólo producen personas “incultas por exceso de información”, “depósitos ambulantes de información”, por supuesto, no digerida.

La educación moderna debe hacer un cambio de paradigma, es decir, un cambio de la idea central que la define. El nuevo profesor será un animador, un experto en la mayéutica, que buscará situaciones problemáticas de la vida y las propondrá a sus alumnos, situaciones que tengan en cuenta todas las dimensiones del ser humano: inteligencia, sensibilidad y cuerpo, ya que la neurociencia actual nos demuestra que existe esa relación estrecha, como señalamos, entre la inteligencia y la afectividad; esto le permitirá llevar a sus alumnos a lo que pueden llegar a ser. Los nuevos alumnos buscarán las soluciones trabajando con la información que está por todas partes en su ambiente. La creatividad deberá presentarse como un proceso lúdico colectivo, al estilo de los diálogos de Platón, o los jardines de infancia de Fröbel y Montessori. El mismo Einstein, como ya indicamos, decía que "el arte más importante de un maestro es saber despertar en sus alumnos la alegría de conocer y crear”. 
Un aspecto de gran importancia de la Nueva Educación, lo constituye el fomento de la cooperación, el trabajo en equipo y la dinámica de grupo; no se trata de fomentar la competitividad mal orientada y la rivalidad, que tantos sentimientos negativos generan. Esto lo exige la poliédrica complejidad de las realidades actuales, donde todos los puntos de vista pueden ser valiosos. Por ello, el fomento de la cooperación es algo exigido para que los procesos creadores tengan éxito. Frecuentemente, se insinúa y aconseja ser tolerantes con las ideas de los demás; no sólo debemos tolerar los puntos de vista de los otros -eso es lo mínimo que podemos hacer, sino implorar que nos los ofrezcan para enriquecer el nuestro, usando el famoso "principio de complementariedad" de los enfoques, tan importante hoy día en la teoría del conocimiento.

Es necesario, por lo tanto, que la Nueva Educación enfatice que resulta imposible que se pueda demostrar la prioridad o exclusividad de una determinada disciplina, teoría, modelo o método, o cualquier otro instrumento conceptual que se quiera usar, para la interpretación de una realidad específica. La Nueva Educación no sólo debe respetar esta diversidad de valores y perspectivas, sino que debe inculcar en los alumnos que ésta es la mayor riqueza que posee el género humano. Por esto, sólo con un diálogo fecundo y con el intercambio con otros seres humanos podemos lograr enriquecer y complementar nuestra percepción de la realidad.

Docencia Actualizada. Muchos docentes hacen de su asignatura algo casi imposible de comprender, por usar únicamente actividades del hemisferio izquierdo, utilizando medio cerebro. La gran mayoría de las disciplinas académicas tienen grandes cantidades de conocimientos que se expresan tanto analítica como sintéticamente, es decir, tanto racional y secuencialmente como gráfica y estereognósicamente, siendo casi siempre una forma mejor que la otra. Esto depende mucho del "estilo cognitivo" propio de cada persona. De todos modos, siempre es preferible la integración de las dos formas, ya que una utiliza el proceso consciente y la otra el inconsciente con su inmensa riqueza de información almacenada. Un buen gráfico, diseño, mapa, diagrama, tabla, matriz o cuadro, a colores y proporcional, como se encuentran en los buenos textos y facilitan hoy los programas computacionales, permite una comprensión rápida y cabal de muchas realidades imposibles de captar numérica, secuencial, racional o verbalmente. Por ello, el buen docente trata siempre de hacer visualizable lo que expresa racionalmente. Como dicen los chinos, una imagen vale más que mil palabras. Además, la presentación de ambas formas, no es usar dos formas solamente, sino dos formas y la interacción entre las dos, algo que enriquece enormemente a cada una.

Orientación Efectiva. La Orientación que necesitamos hoy día -ya sea la relacionada con la Vocación Profesional o el Asesoramiento Psicológico- no pueden ser entendidas si las descontextualizamos de los ambientes históricos en que se dan. Cada período histórico tiene sus peculiaridades y sus características y, por consiguiente, también sus exigencias. 
Con la evolución y diversificación del trabajo, y con el casi infinito número de profesiones, especializaciones y áreas ocupacionales, estamos ante el imperativo de otro cambio fundamental: la necesidad de centrar la Orientación Vocacional en el desarrollo de la persona, sus valores y el significado que tiene su área de trabajo para su auto-realización personal.

Son muchas las razones que avalan y claman por la necesidad de dicho cambio, entre otras, las siguientes: el hecho que mucha orientación vocacional está dirigida básica y únicamente hacia la población de clase media, descuidando las clases más pobres y desposeídas; el énfasis que la Psicología Humanista pone en el derecho que todo ser humano tiene a lograr su plena auto-realización; la igualdad de derechos que la sociedad actual reconoce a toda minoría, ya sea racial, étnica, social o de otra clase; la desatención que han tenido importantes áreas de trabajo que no se ubican en la estructura ocupacional empresarial, como es el trabajo femenino del hogar, el cuidado de niños, ancianos o minusválidos; la estaticidad de las teorías y modelos de la Psicología Vocacional y del Desarrollo de las Carreras en un mundo de veloces cambios, interacciones y procesos de transacción; el etnocentrismo disciplinar que se observa en el área y que se resiste a la incorporación de nuevas ideas, enfoques y perspectivas; y el androcentrismo que, aunque en muchas partes ya ha sido superado, en otras todavía se resiste fuertemente. Es indudable que el desconocimiento de esta serie de razones en el desarrollo de la literatura vocacional socava los cimientos y descalifica cualquier pretensión de validez científica que dicha literatura pueda reclamar.

En la actualidad, pareciera que los "signos de los tiempos" claman hacia una actividad profesional en la Orientación Vocacional que se centre más en "la vida de las personas" y el significado que el trabajo que desempeñan tiene para su propia autorealización; todo lo demás pasaría a un segundo plano. En efecto, el concepto de carrera está más relacionado con el ethos de un individualismo egocéntrico y una concepción del yo más etnocéntrica, mientras que el concepto más general de trabajo lleva inherentes unos valores personales que le dan sentido propio y particular; por ello, el trabajo siempre ha sido entendido como una forma central y crítica de la acción humana, como un esfuerzo o actividad que un individuo realiza con el fin de proveer bienes y servicios de valor a otros; es decir, que el trabajo se considera como "un valor social” por su contribución a la sociedad (Richardson, 1993).

Asesoramiento Psicológico. Los cambios señalados en los puntos anteriores se hacen más necesarios y evidentes en el Asesoramiento Psicológico, ya que esta actividad entra más de lleno e íntimamente en la dinámica personal del ser humano.

Si tuviéramos que escoger un solo concepto para resumir o integrar en él las características o fisonomía psicológica del Asesor que demandan los tiempos que vivimos, tendríamos que usar el concepto de sabiduría, o prudencia, cordura, ponderación, buen criterio o buen juicio, etc. 
Efectivamente, estos términos describen y distinguen al asesor que es hoy día exitoso en su actividad profesional de aquel que no lo es. Son muchas las variables que entran en juego en una relación interpersonal de ayuda. Esas variables no son aleatorias, sino que forman un sistema y constituyen la personalidad del asesorado, por un lado, y la del asesor, por el otro, y ambos grupos estructuran un suprasistema o patrón de relaciones de alto nivel de complejidad, y basta, a veces, descuidar uno solo de estos elementos para que fracasemos en nuestra actividad de ayuda.

La virtud de la prudencia es considerada ya por Aristóteles (frónesis) como una de las cuatro virtudes centrales en el ser humano, y consiste en el recto juicio ante los problemas o dificultades que nos presenta la vida. Por ello, es un concepto transcultural, pues se halla en la gran mayoría de las culturas, tanto de Oriente como de Occidente. En el campo de la Orientación, recibió especial atención en las últimas tres décadas, ante la complejidad de la vida moderna y el fracaso de técnicas simplistas como las defendidas por el positivismo lógico y el conductismo radical.

En su esencia, todos sabemos lo que es un hombre o mujer sabios o prudentes, pero, si queremos describirlos, fácilmente omitiremos aspectos o rasgos importantes. En general, podríamos decir que son personas que poseen una dotación especial, cognitivo-afectiva, que las habilita para enfrentar exitosamente las realidades problemáticas de la vida. Como esta dotación no se adquiere con simples técnicas o en corto tiempo, suele representarse la persona sabia con el semblante de un anciano pensativo.

Sin embargo, es posible adelantar la presencia de esta sabiduría o prudencia, y la vida actual, por su gran complejidad, se lo exige al Asesor Psicológico. Para ello, dicho Asesor deberá esforzarse por adquirir una variedad de características o rasgos personales que constituyen la base de esa virtud cardinal. Estas características, según Sternberg (1990), se centran en las siguientes habilidades: aprender a escuchar a las personas, interés en sus problemas, profunda comprensión y empatía, especial capacidad de auto-conocimiento y de auto-conciencia, habilidad para tener visiones panorámicas de los problemas, capacidad para aprender de los errores y habilidad para reenfocar los posibles significados de las situaciones. Como vemos, estos atributos son muy valorados en la mayoría de las culturas, trascienden sus linderos y, en general, tienen una aplicabilidad universal.

Conviene hacer énfasis en una idea más, sobre la formación del Orientador o Asesor, tomado en sentido amplio: ya sea psicólogo, psiquiatra, terapeuta, educador, orientador, trabajador social o religioso. La educación occidental ha ignorado ampliamente el cultivo de la sabiduría o prudencia en el ser humano, debido a su énfasis en la inteligencia, las matemáticas, las ciencias duras y la tecnología. Son muchas las consecuencias negativas que ha traído esta actitud. Entre ellas, el hecho de que numerosas investigaciones bien realizadas nos señalen que estos profesionales no son más efectivos que los paraprofesionales, o lo son sólo levemente, a pesar de su 
nivel de educación y años de experiencia (Hattie, 2003). Por ello, resulta paradójicamente interesante que un concepto tan viejo y universal como es el de sabiduría, sea propuesto en nuestros tiempos como un “nuevo” paradigma para determinar las características, cualidades y práctica que debe tener un Orientador o Asesor del desarrollo humano altamente efectivo.

Si tomamos el “desarrollo humano” en su forma integral, recordemos que toda persona necesitada, todo grupo humano que requiere atención, se nos presentan haciéndonos un llamado, solicitándonos y hasta rogándonos una ayuda, aunque no lo hagan con un lenguaje verbal, sino con el lenguaje no-verbal, que frecuentemente es el más expresivo y elocuente porque revela dónde está la anomalía, la enfermedad, el desorden o el problema. Y, ante esta situación, se podría, incluso, decir que la verdadera práctica eficaz de la ayuda depende básicamente del nivel de excelencia y de la calidad humana de la persona que la brinda.

Por esto, no debemos olvidar que gran parte del desconcierto personal que sufren muchas personas, de todas las edades, tiene una base de desorientación existencial y, más concretamente, de los valores espirituales. De aquí, que, en las consultas y solicitudes de apoyo personal, hagan preguntas relacionadas con el origen y destino de nuestro universo, sobre el significado de la vida, la existencia de Dios y otras similares con trasfondo existencial y espiritual. Como el trato de este tema nos llevaría lejos, remito al lector interesado a la respuesta que personalmente suelo dar en estos casos, y que la encuentran en el último capítulo (el 25) de mi reciente obra (2008), capítulo que también pueden descargar de una de mis Páginas de Internet, cuya dirección figura en la primera página de este estudio, o, más directamente, en: http://miguelmartinezm.atspace.com/libro8cap25 sersupremo.html.

\section{Conclusiones}

La Educación Humanista, entendida y practicada con la riqueza de la dotación que posee todo ser humano, será capaz de formar las generaciones del futuro, mejor equipadas en sus cabezas y más honestamente sensibilizadas en sus corazones.

Nuestra docencia, los conocimientos que transmitimos y los métodos que utilizamos para la búsqueda de otros nuevos, necesitan, hoy más que nunca, una superación de la inercia mental, que rige gran parte de nuestro comportamiento, y la creación de un clima permanente de libertad mental, una atmósfera general, integral y global que estimule, promueva y valore el pensamiento divergente, la discrepancia razonada, la oposición lógica y la crítica fundada; todo lo cual implica equilibrio y síntesis entre las posiciones radicales o extremas, diálogo entre los diferentes puntos de vista o enfoques, pues más que antagónicos evidenciarán ser complementarios, y, sobre todo, la conciencia de que nuestra juventud tiene una sensibilidad especial para captar los signos que marcan los cambios de su tiempo; 
y, por todo ello, la conciencia de que el mejor profesor no es el que tiene buenas respuestas, sino el que sabe hacer buenas preguntas.

Por último, quiero detenerme en la última característica señalada, la Ética, pues, en cierto modo, de ella dependen todas las demás. La Revolución Francesa, que se considera como la revolución por excelencia, puso entre sus rasgos de identificación un concepto clave: la fraternidad (la fraternité; los otros eran la liberté y la égalité). Es más que interesante hacer ver que todas las religiones, tanto las occidentales como las orientales, resumen sus normas, preceptos y mandamientos en uno que condensa toda su ética: "no hacer al otro lo que uno no quiere para sí", o, en su expresión positiva, "tratar al otro como uno quisiera ser tratado"; en fin de cuentas, tratan de establecer una fraternidad, de considerar al otro como un "hermano".

Llama, también, nuestra atención el hecho que, hoy día, los estudios antropológicos estén demostrando, a través de las investigaciones sobre el ADN, que toda la humanidad existente actualmente desciende de un único tronco, es decir, de una sola pareja biológica. Por lo tanto, tendríamos una razón más para hablar de fraternidad, para dialogar con nuestros hermanos, para comprendernos y para construir con ellos una vida familiar más feliz y generalizada. 


\section{Bibliografía}

Allport, G. (1966), La personalidad: su configuración y desarrollo, Herder, Barcelona.

Bertalanffy, L. von (1981), "Historia y situación de la teoría general de sistemas”, en Bertalanffy, L. von et al., Tendencias en la teoría general de sistemas, Alianza, Madrid.

Bogen, J.E. y G.M., Bogen (1976). Creativity and bisected brain, en Rothenberg y Hausman, 1976.

Bühler, Ch. (1967). «Human life as a whole”, en Bugental J. (dir.), Challenges of Humanistic Psychology. Nueva York: McGraw-Hill, 1967.

CIRET-UNESCO (1997). ¿Qué universidad para el mañana? Hacia una evolución transdisciplinaria de la universidad. Declaración y recomendaciones del Congreso Internacional sobre Transdisciplinariedad, Locarno (Suiza), Mayo, 1997.

Idem (2000). International transdisciplinary conference. Zurich, Febr 27Marzo 1, 2000.

Goleman, D. (1996). La inteligencia emocional: por qué es más importante que el cociente intelectual. Buenos Aires: Javier Vergara.

Hattie, J. (2003). Distinguishing Expert Teachers from Novice and Experienced Teachers. Consulta del 05-05-2009 en: http://www.acer.edu.au/ documents/RC2003_Hattie_TeachersMakeADifference.pdf.

Martínez, M. (2004). La psicología humanista: Un nuevo paradigma psicológico, 2da edic., México: Trillas.

Idem (2006a). La nueva ciencia: Desafío, lógica y método. México: Trillas.

Idem (2006b). Comportamiento humano: Nuevos métodos de investigación, $2^{a}$ edic., México: Trillas.

Idem (1993¹ $1997^{2}$, 2006c). El paradigma emergente: Hacia una nueva teoría de la racionalidad científica. Barcelona: Gedisa, 1993' México: Trillas $1997^{2}$, 2006c.

Idem (2006d). Ciencia y arte en la metodología cualitativa, 2da edic., México: Trillas.

Idem (2007a). La investigación cualitativa etnográfica en educación, $3^{\mathrm{a}}$ edic., México: Trillas. 
Idem (2007b). Evaluación Cualitativa de Programas. México: Trillas.

Idem (2008). Epistemología y Metodología Cualitativa en las Ciencias Sociales. México: Trillas.

Idem (2009, en prensa). Nuevos paradigmas en investigación. Caracas: Alfa.

Idem, Páginas de Internet: http://prof.usb.ve/miguelm; http:// miguelmartinezm.atspace.com.

Morin, E. (2002). La cabeza bien puesta. Buenos Aires: Nueva Visión.

Ortega y Gasset, J. (1968), Misión de la universidad. Madrid: Revista de Occidente.

Pooper, K. (1977). Búsqueda sin término: Una autobiografía intelectua. Madrid: Tecnos.

Richardson, M.S. (1993). Work in people’s lives: A location for counseling psychologists, J. of Counseling Psychology, 40: 25-433.

Rivadulla, A. (1986). Filosofía actual de la ciencia. Madrid: Tecnos.

Rogers, C. (1972). El proceso de convertirse en persona. Buenos Aires: Paidós.

Idem (1975). Libertad y creatividad en educación. Buenos Aires: Paidós.

Idem (1980a). El poder de la persona México: El Manual Moderno.

Idem (1980b). A way of being: The latest thinking on a person-centered approach to life, Boston: Houghton.

Rothenberg, A. y C.R. Hausman (1976). The creativity question. Durham: Duke Univ. Press.

Solschenitzin, A. (1974). El primer círculo. Barcelona: Bruguera.

Sternberg, R.J. (Ed.) (1990). Wisdom: its nature, origins, and development. Nueva York: Cambridge Univ. Press.

Torrance, E.P. (1971). Tests para evaluar las habilidades creativas, en Davis, G. y Scott, J., Estrategias para la creatividad. Buenos Aires: Paidós.

UNESCO (1979). Enfoque sistémico del proceso educativo. Madrid: Anaya/ Unesco.

Idem (1997). Declaración Universal sobre el Genoma Humano y los De- 
Polis, Revista de la Universidad Bolivariana, Volumen 8, $N^{\circ}$ 23, 2009

rechos Humanos, aprobada el 11 de noviembre de 1997.

Idem (1998a). Transdisciplinarity: Towards integrative process and integrated knowledge. Simposio en Royaumont (Francia). En : http:// firewall.unesco.org/philosophy/transdisciplinarity. Consulta del 03 Abril 2009.

Idem (1998b). Declaración de París sobre la Educación. Publicado en muy diferentes fuentes e idiomas. 